\title{
Transformation pathways and acute toxicity variation of 4-hydroxyl benzophenone in chlorination disinfection process
}

\author{
Wei Liu $^{\text {a, b, } 1 \text {, Dongbin Wei }}{ }^{\text {a, b, * }}$, Qi Liu ${ }^{\text {a, }}{ }^{\text {, Yuguo Du }}{ }^{\text {a, b }}$ \\ a State Key Laboratory of Environmental Chemistry and Ecotoxicology, Research Center for Eco-Environmental Sciences, Chinese Academy of Sciences, \\ Beijing 100085, PR China \\ ${ }^{\mathrm{b}}$ University of Chinese Academy of Sciences, Beijing 100049, PR China
}

\section{H I G H L I G H T S}

- 7 transformation products in $4 \mathrm{HB}$ chlorination disinfection system were identified.

- Transformation pathways of $4 \mathrm{HB}$ during chlorination disinfection were proposed.

- Acute toxicity increased after chlorination due to the formation of 3,5-dichloro-4HB.

- The transformation mechanisms of $4 \mathrm{HB}$ can be repeated in ambient water matrices.

\section{A R T I C L E I N F O}

\section{Article history:}

Received 5 February 2016

Received in revised form

1 April 2016

Accepted 3 April 2016

Available online 13 April 2016

Handling Editor: Xiangru Zhang

\section{Keywords:}

Chlorination

4-Hydroxyl benzophenone

Transformation mechanisms

Disinfection

Toxicity

\begin{abstract}
A B S T R A C T
Benzophenones compounds (BPs) are widely used as UV filters, and have been frequently found in multiple environmental matrices. The residual of BPs in water would cause potential threats on ecological safety and human health. Chlorination disinfection is necessary in water treatment process, in which many chemicals remained in water would react with disinfectant chlorine and form toxic byproducts. By using ultra performance liquid phase chromatography quadrupole time of flight mass spectrometer (UPLC-QTOF-MS), nuclear magnetic resonance (NMR), the transformation of 4-hydroxyl benezophenone $(4 \mathrm{HB})$ with free available chlorine $(\mathrm{FAC})$ was characterized. Eight major products were detected and seven of them were identified. Transformation pathways of $4 \mathrm{HB}$ under acid, neutral, and alkaline conditions were proposed respectively. The transformation mechanisms involved electrophilic chlorine substitution of $4 \mathrm{HB}$, Baeyer-Villiger oxidation of ketones, hydrolysis of esters and oxidative breakage of benzene ring. The orthogonal experiments of $\mathrm{pH}$ and dosages of disinfectant chlorine were conducted. The results suggested that $\mathrm{pH}$ conditions determined the occurrence of reaction types, and the dosages of disinfectant chlorine affected the extent of reactions. Photobacterium assay demonstrated that acute toxicity had significant increase after chlorination disinfection of $4 \mathrm{HB}$. It was proved that 3,5dichloro-4HB, one of the major transformation products, was responsible for the increasing acute toxicity after chlorination. It is notable that, $4 \mathrm{HB}$ at low level in real ambient water matrices could be transformed during simulated chlorination disinfection practice. Especially, two major products 3-chloro-4HB and 3,5-dichloro-4HB were detected out, implying the potential ecological risk after chlorination disinfection of $4 \mathrm{HB}$.
\end{abstract}

() 2016 Elsevier Ltd. All rights reserved.

\footnotetext{
* Corresponding author. State Key Laboratory of Environmental Chemistry and Ecotoxicology, Research Center for Eco-Environmental Sciences, Chinese Academy of Sciences, Beijing 100085, PR China.

E-mail address: weidb@rcees.ac.cn (D. Wei).

1 Both authors are equal contributors.
}

\section{Introduction}

With the increasing concern about the effects of ultraviolet (UV) irradiation, more and more UV filters especially organic types with better sun protection factors, higher photo stability, and better water resistance have been produced and used throughout the last decades. Besides cosmetics such as lotions, shampoos, and lipsticks in personal care products, UV-filters are also widely used in 
insecticides, agricultural chemicals, pharmaceuticals and material preservatives, e.g. textiles and numerous other products (Christin et al., 2007; Roelandts et al., 1983; Stenback, 1977; Tomson et al., 1981). Benzophenones (BPs), one class of commonly used UVfilters, have wide absorption wavelength range at $200-400 \mathrm{~nm}$. $B P s$ are effectively used in preventing some skin diseases even skin cancer, for reducing the harms of UVA (320-400 nm) and UVB $(290-320 \mathrm{~nm}$ ) to human body completely (Moloney et al., 2002). In addition, BPs are also used as agricultural chemicals, flavor ingredients and UV stabilizers in plastic surface coatings for food packaging and in the manufacture of cosmetics and other personal care products due to their low cost (Suzuki et al., 2005; Zenker et al., 2008). The maximum authorized concentration of 2hydroxy-4-methoxy-BP (BP-3) in sunscreens is $10 \%$ in EU, $6 \%$ in USA, 2,2'-dihydroxy-4-methoxy-BP (BP-8) is 3\% in Korea (EEC, 1983; FDA, 1999; Jeon et al., 2006). 2-Hydroxy-4-methoxy-5sulfonic acid BP (BP-4) is permitted for use in cosmetics at a maximum concentration of $10 \%$ in Japan and Australia (SJP, 1985; TGA, 2003). As a result, a large amount of residual BPs and their metabolites enters into the aqueous environment via washing off from skin and clothes, or discharging of sewage and swimming pool waters (Kim and Choi, 2014). The concentration of BP-4 ranged from 237 to $1481 \mathrm{ng} \mathrm{L}^{-1}$ in wastewater from Galicia (NW Spain) (Rodil et al., 2008). 2,4-Dihydroxy-BP (BP-1) was detected with the mean concentration of $47 \mathrm{ng} \mathrm{L}^{-1}$ in 25 rivers in Korea, and benzhydrol, a major metabolite of benzophenone was detected with the highest concentration of $204 \mathrm{ng} \mathrm{L}^{-1}$ as well. Meanwhile, the concentration of BP-3 and BP-8 ranged from 730 to 3880 and $500-4170 \mathrm{ng} \mathrm{kg}^{-1}$ in soil samples, respectively (Jeon et al., 2006). It has been proved that human bodies would absorb and accumulate BPs after skin administration. BP-3 was detected up to $445 \mathrm{ng} \mathrm{g}^{-1}$ lipid in human breast milk samples (Hany and Nagel, 1995), up to $40 \mu \mathrm{g} \mathrm{L}^{-1}$ in urine samples (Zwiener et al., 2007). BP-1, a metabolite of BP-3, has also been detected in urine after application of commercially available sunscreen products to the skin (Felix et al., 1998).

BPs are bioaccumulative in organisms due to their hydrophilicity, which would make adverse biological effects. For example, BPs exhibited both estrogenic and anti-androgenic properties in a variety of organisms, exerted auterotrophic effect in vivo test, stimulated cell proliferation of human breast cancer cell line MCF-7 (Michigan Cancer Foundation7) and increased the secretion of tumor marker pS2 (an estrogen-induced protein) in vitro (Balmer et al., 2005; Ma et al., 2003; Schlumpf et al., 2001; Schreurs et al., 2005; Zenker et al., 2008). Moreover, some BPs such as benzophenone, BP-3 and BP-8, 2,3,4-trihydroxy-BP (BP-20) have been reported to have potential genotoxic effects (Fluck et al., 1976; French, 1992; Jeon et al., 2007; Mortelmans et al., 1986; Zeiger et al., 1987). Some BPs have also been observed obvious genotoxic effects at high milligram per liter level (Zhao et al., 2013). A current epidemiological survey suggested that male exposure to 2,2 ',4,4'tetrahydroxy-BP (BP-2) or 4-hydroxyl benzophenone (4HB) may diminish couples' fecundity by about 30 percent, resulting in a longer time to pregnancy (Louis et al., 2014).

Disinfection is one of necessary processes for producing tap water, relaimed water, and swimming pool water. Chlorine is still one of the most popular disinfectants in the world due to its high efficiency, convenience and low cost. However, except for killing pathogens, chlorine may react with the residual chemicals and natural organic matter in water, and generate some unintended toxic disinfection by-products (DBPs). More than 600 DBPs have been identified in drinking water, and many of them are mutagenic or carcingenic (Richardson, 1998; Richardson et al., 2007). During chlorination of BP compounds, halogenated aromatic DBPs might be formed. And recent studies have shown that halogenated aromatic DBPs were significantly more toxic than the regulated trihalomethanes and haloacetic acids (Yang and Zhang, 2013; Pan et al., 2016; Liu and Zhang, 2014). The formation mechanisms and potential ecological or health risk of DBPs should be paid more attention, which would provide scientific reference for optimizing disinfection operating parameters. The substitution and cleavage of two benzene rings of BP-3 and BP-4 in chlorination disinfection have been reported (Negreira et al., 2008, 2012; Xiao et al., 2013). Bromoform was found to be generated from BP-3 during the chlorination of seawater swimming pools (Manasfi et al., 2015). However, the toxicity changes after chlorination disinfection of BPs, identification and formation pathways of toxic products have not been disclosed systematically. It is well known that lots of chemical reactions occur in chlorination disinfection system, and the components in chlorinated solution are quite complex. Furthermore, the target chemicals selected in the previous literature usually had complex molecular structures, which increased the difficulty in identifying products structures and analyzing transformation mechanisms. If a model chemical with simple structure and similar reactivity is selected, it will be quite easier to disclose common transformation characteristics of pollutants comprehensively. Therefore, the present paper focused on the chlorination disinfection of $4 \mathrm{HB}$, identified the main transformation products, and proposed the plausible transformation pathways under acid, neutral and alkaline conditions, respectively. Moreover, the acute toxicity variation of $4 \mathrm{HB}$ after chlorination treatment under different conditions was monitored to screen transformation products with high toxicity. The results of this study would throw more light on the transformation mechanism of BPs in water disinfection treatment, and provide scientific basis to the risk evaluation of this kind of compounds.

\section{Methods and materials}

\subsection{Reagents and instruments}

4HB ( $>97.5 \%$ purity) was purchased from Sigma-Aldrich (St Louis, MO, USA) which was used directly without further purification. Salts including $\mathrm{HOAc}$ (acetic acid), $\mathrm{NaOAc}$ (sodium acetate), $\mathrm{Na}_{2} \mathrm{CO}_{3}$ (sodium carbonate), $\mathrm{Na}_{2} \mathrm{HPO}_{4} \cdot 12 \mathrm{H}_{2} \mathrm{O}$ and $\mathrm{NaH}_{2} \mathrm{PO}_{4} \cdot 2 \mathrm{H}_{2} \mathrm{O}$ for preparing buffer $(\mathrm{pH}=4.6,7.5$ and 11.0 with the concentration of $0.02 \mathrm{M}$ ), $\mathrm{KH}_{2} \mathrm{PO}_{4}, \mathrm{NaCl}$ and $\mathrm{Na}_{2} \mathrm{SO}_{3}$ for toxicity test medium and quenching solutions, were purchased from Sigma-Aldrich (St Louis, MO, USA). Yeast extract, tryptone and glycerol were obtained from BD (Franklin Lakes, NJ, USA). Methanol and acetone for HPLC analysis were obtained from Fisher Sci (Fair Lawn, NJ, USA). Dimethylsulfoxide (DMSO) was purchased from Amresco (Solon, $\mathrm{OH}, \mathrm{USA}$ ). The $\mathrm{NaClO}(8 \%)$ aqueous solution was purchased from Wako Co (Tokyo, Japan). The test bacteria Photobacterium phosphoreum T3 Straus was provided as freeze-dried powder by the Institute of Soil Science, Chinese Academy Sciences, Nanjing, China. The ultrapure water used in solution preparation and dilution was produced by a Milli-Q purification system (Millipore, Billerica, MA, USA). An Ultimate3000 UPLC (Dionex, USA) and QTOF-MS (micrOTOF QII, Bruker, Germany) were used to separate and identity the main transformation products of $4 \mathrm{HB}$ after chlorination in different buffer system.

\subsection{Chlorination experiments}

Considering the relative distribution and properties of free 
available chlorine (FAC) species under different $\mathrm{pH}$ conditions (Fig. S1), the chlorination experiments were conducted at three $\mathrm{pH}$ values 4.6 (100\% as $\mathrm{HOCl}), 7.5\left(50 \%\right.$ as $\mathrm{HOCl}$ and $50 \%$ as $\left.\mathrm{ClO}^{-}\right)$and $11.0\left(100 \%\right.$ as $\left.\mathrm{ClO}^{-}\right)$for exploring the chlorination mechanisms of $4 \mathrm{HB}$ within a relatively wide $\mathrm{pH}$ range. To maintain the $\mathrm{pH}$ value within 0.1 unit of variance during the reaction period, $0.02 \mathrm{M}$ acetate buffer $(\mathrm{pH}=4.6)$, phosphate buffer $(\mathrm{pH}=7.5)$, and carbonate buffer ( $\mathrm{pH}=11.0$ ) were used.

The chlorination reaction was conducted in a $1000 \mathrm{~mL}$ borosilicate glass conical flask, which was wrapped with aluminum foil and placed in a water bath with a magnetic stirring apparatus to maintain the reaction temperature at $25 \pm 0.5^{\circ} \mathrm{C}$. To avoid missing the detection of the trace chlorination products and make a more comprehensive research, the initial concentration of $4 \mathrm{HB}$ was set as $2 \mathrm{mM}$ in $500 \mathrm{~mL}$ of buffer solutions $(0.02 \mathrm{M})$, respectively. The cosolvent, methanol concentration in reaction system was less than 1\% (Schwarzenbach et al., 2003). The chlorination reaction was initiated by adding certain amount of FAC. The initial doses of FAC were set as $0,1,3,5,10$ and 15 molar equivalent to $4 \mathrm{HB}$, respectively. Five milliliters of samples were subsequently collected at certain time intervals from the reaction system and a slightly excessive sodium sulfite (1.2 molar equivalent of sulfite to FAC) was added immediately to quench the reaction.

\subsection{Sample preparation}

The samples were freeze-dried by a lyophilizer (FD-1D-50, Beijing, China), and $4 \mathrm{~mL}$ of mixed solvents (50\% methanol and $50 \%$ acetone) was added to extract organic components. The extract was filtered through a $0.22 \mu \mathrm{m}$ glass fiber membrane to remove undissolvable inorganic salts. One milliliter of the filtrate was taken to detect the residual $4 \mathrm{HB}$ and transformation products by UPLCQTOF-MS. Two milliliters of filtrate was taken to be dried with a gentle flow of ultrapure nitrogen gas, and the solid residue was redissolved in $400 \mu \mathrm{L}$ DMSO as stock solution. For the photobacterium acute toxicity test, the stock solution was diluted with $3 \% \mathrm{NaCl}$ aqueous solution. The content of DMSO in the exposure solution for the bioassay was less than $1 \%(\mathrm{v} / \mathrm{v})$ at which had been proved to be no significant influence on photobacterium bioassay (Grzegorz et al., 1997).

\subsection{Acute toxicity test}

The pretreated sample was diluted into a series of solutions with gradient concentrations, and added into a 96-well microplate. $\mathrm{NaCl}$ solution (3\%) was set as negative control, and $\mathrm{Hg}^{2+}$ (prepared with $\mathrm{HgCl}_{2}$ ) was set as positive control to obtain the calibration curve. The volume of sample or $\mathrm{Hg}^{2+}$ in each well was $180 \mu \mathrm{L}$. Then $20 \mu \mathrm{L}$ of pre-cultured $P$. Phosphoreum bacteria suspension was added into each well and mixed sufficiently. After a $15 \mathrm{~min}$ of shake and exposure period at $22 \pm 1{ }^{\circ} \mathrm{C}$, the bioluminescence intensity in each well was measured by Synergy ${ }^{\mathrm{TM}} 2$ Multi-Mode Microplate Reader (Biotek, USA). Toxicity was expressed as the luminescence intensity inhibition ratio (Ir), which could be described as follows:

$I r=\frac{L_{N C}-L_{\text {sample }}}{L_{N C}} \times 100 \%$

Where, $L_{N C}$ represents the luminescence intensity of negative control, $L_{\text {Sample }}$ represents the luminescence intensity of sample. For each toxicity test, two dose-response curves could be obtained, one was of positive reference substance $\mathrm{Hg}^{2+}$, and the other was of tested sample. Based on the two dose-response curves, the half maximal effective concentrations (EC50) were calculated for positive reference substance $\mathrm{Hg}^{2+}$ and samples, respectively (Ye et al.,
2011). In order to visually reflect the toxicity of samples before and after disinfection of $4 \mathrm{HB}$ under various conditions, the toxicity results of samples were converted into equivalent concentration of positive reference substance $\mathrm{Hg}^{2+}$. Specifically, after acquiring the dose-response curves of $\mathrm{Hg}^{2+}$ (X-axis is mass of $\mathrm{Hg}^{2+}, \mathrm{mol}$ ) and sample (X-axis is volume of sample, $\mathrm{L}$ ), EC50 values for $\mathrm{Hg}^{2+}$ and samples were calculated, respectively. The ratio of $\mathrm{EC}^{2} \mathrm{O}_{\mathrm{Hg}}^{2+}$ to EC50 5 Sample, defined as equivalent concentration of $\mathrm{Hg}^{2+}(\mathrm{M})$, indirectly reflects the toxicity of one sample. The control trials of three buffer solutions proved that buffer salts had no effect on the toxicity test of the P. Phosphoreum bacteria.

\subsection{Liquid chromatography-mass spectrometry}

The residual of $4 \mathrm{HB}$ and possible transformation products were separated by an ultra performance liquid chromatography (Ultimate 3000, Dionex, USA) system with Agilent SB-C18 column $(4.6 \times 150 \mathrm{~mm}, 5 \mu \mathrm{m})$, and analyzed by quadrupole-time of flight mass spectrometer (micrOTOF QII, Bruker, Germany). The mass spectrometer has high resolution (resolution $>16,500$ FWHM (full width at half maximum) and $\Delta \mathrm{M} / \mathrm{M}<2 \mathrm{ppm}$ ), which can provide accurate molecular mass for identifying the possible structure of the transformation products. Injection volume was $1 \mu \mathrm{L}$ and flow rate was $0.4 \mathrm{~mL} / \mathrm{min}$, gradient elution was mixture of $0.1 \%(\mathrm{v} / \mathrm{v})$ formic acid aqueous solution and methanol. The gradient elution method is described in Table S1. The MS analyses were conducted using negative mode electrospray ionization $\left(\mathrm{ESI}^{-}\right.$) over a mass scan range of $50-1000 \mathrm{~m} / \mathrm{z}$. The mass spectrometer fragmentation voltage was set at $175 \mathrm{eV}$. Temperature of spray chamber and dry gas flow rate were set at $250{ }^{\circ} \mathrm{C}$ and $6 \mathrm{~L} / \mathrm{min}$, respectively.

\subsection{Synthesis of 3,5-dichloro- $4 H B$}

Firstly, $0.4 \mathrm{~g} 4 \mathrm{HB}$ and $0.2 \mathrm{~mL} \mathrm{NaClO}(8 \%)$ solution were added into a $250 \mathrm{~mL}$ round bottom flask containing $100 \mathrm{~mL}$ of $0.02 \mathrm{M}$ carbonate buffer solution ( $\mathrm{pH} \mathrm{10)}$ ). After stirring $2 \mathrm{~h}, 0.24 \mathrm{~mL}$ of sulfite solution $(1 \mathrm{M})$ was assed to quench the reaction. The reaction solution was filtered through $0.22 \mu \mathrm{m}$ glass fiber membrane, and the solid was collected. The solid was re-dissolved in $0.5 \mathrm{~mL}$ methanol and the solution was evenly applied on a line $1.5 \mathrm{~cm}$ from the bottom edge of a $20 \times 20 \mathrm{~cm}$ silica gel plate (TLC Silica gel 60 F254, Merck, Germany) by using capillary. After evaporating off the solvent methanol, the silica gel plate was placed into a transparent separation chamber containing mixed solvents (petroleum ether: ethyl acetate $=2: 1, \mathrm{v} / \mathrm{v}$ ) with a depth of less than $1 \mathrm{~cm}$. The chamber was closed with a glass cover. The solvents carried the products up the plate (elute and separate the products). The plate was removed from the chamber before the solvents front almost reached the top of the stationary phase. After drying, scraped off the silica gel adsorbed the target product (3,5-dichloro-4HB), then extracted it into methanol and filtrated. The filtrate was dried with gentle $\mathrm{N}_{2}$ flow, and stocked for further anlaysis.

\subsection{Nuclear magnetic resonance (NMR)}

In order to confirm the molecular structure of some key transformation products in chlorination disinfection system, the ${ }^{1} \mathrm{H}$ NMR and ${ }^{13} \mathrm{C}$ NMR spectra were recorded on a Bruker ARX 400 spectrometer for solutions in deuterated- $\mathrm{CHCl}_{3}$, and the chemical shifts were given in ppm downfield from an internal tetramethylsilane standard. Before the nuclear magnetic resonance experiment, thin layer chromatography was used to acquire the high purity product. 


\section{Results and discussion}

\subsection{Identification of transformation products}

According to the distribution of chlorine species and the influence of chlorine dosages, the orthogonal experiments were respectively conducted with different FAC dosages (0-, 1-, 3-, 5-, 10and 15-equivalents to $4 \mathrm{HB}$ ) under three $\mathrm{pH}$ conditions ( $\mathrm{pH} 4.6,7.5$, 11.0) to characterize the transformation behaviors and acute toxicity changes. It was found that the transformation behaviors of $4 \mathrm{HB}$ were strongly dependent on the operating conditions (e.g., $\mathrm{pH}$, FAC dose). Fig. S2 shows the chromatographic peaks of major products of $4 \mathrm{HB}$ after chlorination with 5-equiv FAC under three $\mathrm{pH}$ conditions, respectively.

From the base peak chromatogram, 8 major products were found. Among them, 7 products were identified. Fig. S3 shows the mass spectrum information, isotopic peaks of the products and the identified structural formula. The high resolution mass spectrometer (resolution $>16,500 \mathrm{FWHM}$ and $\triangle \mathrm{M} / \mathrm{M}<2 \mathrm{ppm}$ ) used in this study could provide accurate molecular mass, true isotopic pattern, and high sensitivity, which are beneficial to structure identification of products. Take monochlorinated product P2 for example, from the mass spectrum as shown in Fig. S3, the exact molecular weight is $m / z 231.0246 / 233.0216$, the intensity ratio of isotopic peaks is about $3: 1$. It can be determined that one hydrogen atom was substitute by one chlorine atom on one benzene ring. Meanwhile, considering the orientation effect of hydroxyl group, it is easily to determine the structure of P2. With the similar method, the molecular structures of products P5 and P6 were identified. Since product P5 is a key intermediate during the chlorination transformation of $4 \mathrm{HB}$, it was synthesized, and its NMR spectrum was obtained to verify its absolute structure. Fig. S4 shows the ${ }^{1} \mathrm{H}$ NMR and ${ }^{13} \mathrm{C}$ NMR spectra, which provides solid evidence to determine the structure of P5. The assignment of chemical shifts for $4 \mathrm{HB}$ and $\mathrm{P} 5$ are listed in Text S1. Product $\mathrm{P} 4$ has one more oxygen atom than that in $\mathrm{P} 5$, and the possible reason is the oxidation of ketone group into ester group by FAC. This reaction is named Baeyer-Villiger oxidation, which has been reported in our previous study (Xiao et al., 2013).

Except for the chlorinated and ester compounds, P3' and P4' were detected in chlorination system as well. According to the MS ${ }^{1}$ information, the structure of parent compound $4 \mathrm{HB}$ and the components in buffer solutions, we conjectured that they were acetonylation derivatives of intermediate phenolics by $\mathrm{CH}_{3} \mathrm{COOH}$ in the buffer solution. In order to affirm this suppose, the acetate buffer system (HOAc-NaOAc, pH 4.6) was replaced by phosphate buffer system $\left(\mathrm{Na}_{2} \mathrm{HPO}_{4}-\mathrm{KH}_{2} \mathrm{PO}_{4}, \mathrm{pH} 4.6\right)$, and the chlorination experiment was performed again. Products P3' and P4' were not detected in the phosphate buffer system, implying $\mathrm{P}^{\prime}$ ' and $\mathrm{P} 4$ ' were acetonylation derivatives from P3 and P4, respectively. Fig. S5 shows the base peak chromatogram of products in two different buffer systems with $[4 \mathrm{HB}]_{0}:[\mathrm{FAC}]_{0}=1: 5$.

Because of the instability of P1 under the ionization conditions of ESI, MS ${ }^{2}$ spectrum was almost same as $\mathrm{MS}^{1}$. The molecular structure of P1 was identified according to the information of molecular ion and fragment ions shown in Fig. S6. With the collision of insert gas, the molecular ions would lose some pieces and generate sequence fragment ions. From Fig. S6, it can be seen that two $\mathrm{HCl}$ molecules, a $\mathrm{CO}_{2}$ molecule, and $-\mathrm{CO},-\mathrm{C}_{2} \mathrm{H}_{2}$ fragments were sequentially broken down from the molecular ion. Product P1' was detected out in acetate buffer system but not in phosphate buffer system. Based on the identification of P3' and P4', we speculated that P1' might be derivate product of P1 in acetate buffer system, but the specific structure of P1' can not be identified yet.

\subsection{Transformation pathways of $4 H B$ in chlorination process}

The proposed transformation pathways of $4 \mathrm{HB}$ chlorination system is shown in Fig. 1, the compounds in the dashed boxes were undetected intermediates under the current instrumental conditions. From the transformation pathways, it can be found that the reaction in alkaline system was the simplest and chlorination occurred only. In neutral system, chlorination, Baeyer-Villiger oxidation and cleavage of benzene ring were occurred. Except for the reactions occurred in neutral system, hydrolysis reaction was found in acid system. Moreover, occurrence of P1', P3'and P4' were the proof of esterification between intermediate products and buffer salts. In fact, the species distribution of FAC determines the reaction types in different $\mathrm{pH}$ systems. At $\mathrm{pH}$ 11.0, the major species of $\mathrm{FAC}$ is $\mathrm{ClO}^{-}$, as electrophilic reagent, chlorination occurred between $\mathrm{ClO}^{-}$and $4 \mathrm{HB}$. At $\mathrm{pH} \mathrm{7.5,} \mathrm{HClO}$ and $\mathrm{ClO}^{-}$were coexisted, $\mathrm{HClO}$ can oxidize carbonyl to ester, and the strong oxidability of $\mathrm{HClO}$ may break the benzene ring as well. At pH 4.6, $\mathrm{HClO}$ is the major species, except of all the reaction types contained in neutral system, hydrolysis could occur either. The hydrolysis of esters easily occurred in both acid and alkaline systems.

\subsection{Influence of $\mathrm{pH}$ values on the transformation of $4 \mathrm{HB}$}

$\mathrm{pH}$ values determine the species distribution of FAC and the target compound. The time-dependent removal behaviors of $4 \mathrm{HB}$ $\left([4 \mathrm{HB}]_{0}=2 \mathrm{mM}\right)$ and the formation of the intermediates P2 and P5 in the FAC chlorination system $\left([\mathrm{FAC}]_{0}=6 \mathrm{mM}\right)$ are shown in Fig. 2. It can be revealed that the reaction reached equilibrium swiftly in three $\mathrm{pH}$ systems. The $4 \mathrm{HB}$ had the highest transformation rate in alkaline system and lowest in acid system, the formation of chlorinated products $\mathrm{P} 2$ and $\mathrm{P} 5$ were the most in alkaline system and the least in acid system. These phenomenas were most likely attributed to the different species of FAC and $4 \mathrm{HB}$ under various $\mathrm{pH}$ conditions. In alkaline system ( $\mathrm{pH} 11.0), \mathrm{ClO}^{-}$is the single species of FAC, and hydroxy group in $4 \mathrm{HB}(-\mathrm{OH})$ is converted into phenolate anion $\left(-\mathrm{O}^{-}\right)$, the phenolate anion easily occurs chlorination substitution with $\mathrm{ClO}^{-}$and accumulates intermediates P2 and P5. In acid system ( $\mathrm{pH} 4.6), \mathrm{HClO}$ is the single species with high redox potential, which rapidly reacts with $4 \mathrm{HB}$ to form chlorinated intermediates P2 and P5. Subsequently, P2 and P5 are oxidized to form ester products and some other products rapidly. As a result, the intermediates P2 and P5 were exhausted and 4HB was remained. The formation of other products also could be understood in the similar way.

\subsection{Influence of FAC dosages on the formation of products}

In order to investigate the effects of the FAC dosages on the transformation of $4 \mathrm{HB}$, different FAC doses were set to react with $4 \mathrm{HB}$ under three $\mathrm{pH}$ conditions $\left([\mathrm{FAC}]_{0}:[4 \mathrm{HB}]_{0}=1,3,5,10\right.$ and 15$)$. The formation and relative contents of major transformation products are shown in Fig. 3. The higher FAC dosage is, the more transformation of $4 \mathrm{HB}$ will be. Some intermediates sequentially increased to maximum concentrations and then decreased. Take P2 for example, it reached a maximum concentration at 3-equiv of FAC and subsequently decreased due to its further transformation with high dosages of FAC. In addition, from Fig. 3, it can be concluded that, with the increasing FAC dosages, P1', P1 and P5 increased continuously and became the major products at $\mathrm{pH} 4.6,7.5$ and 11.0, respectively. 


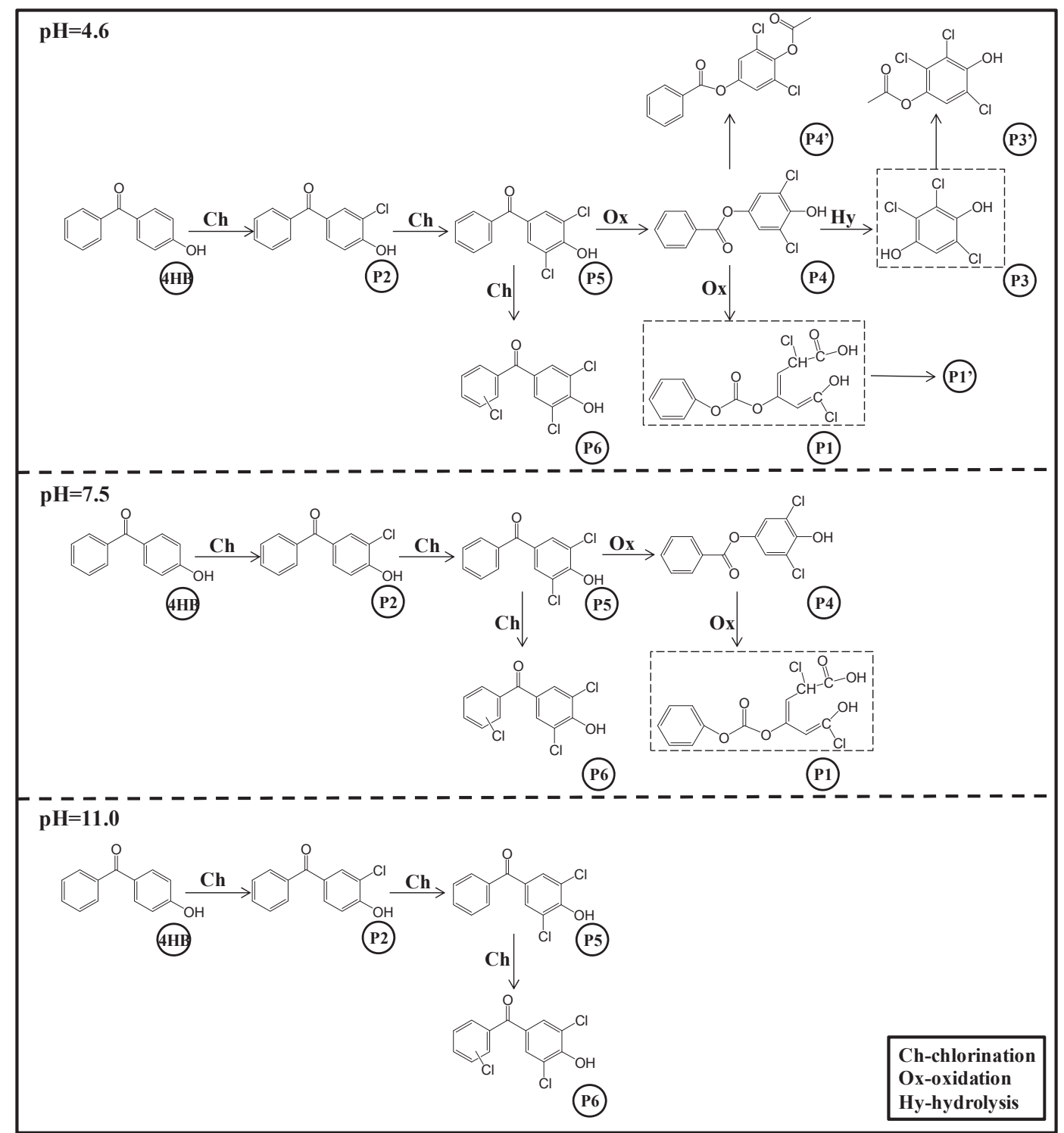

Fig. 1. The proposed transformation pathways of $4 \mathrm{HB}$ in chlorination system ([4HB $]_{0}: 2 \mathrm{mM},[\mathrm{FAC}]_{0}: 20 \mathrm{mM}$, reaction time: $\left.1 \mathrm{~h}\right)$ at three $\mathrm{pH}$ values (pH 4.6, $\mathrm{pH} 7.5$, $\mathrm{pH} 11.0$ ).
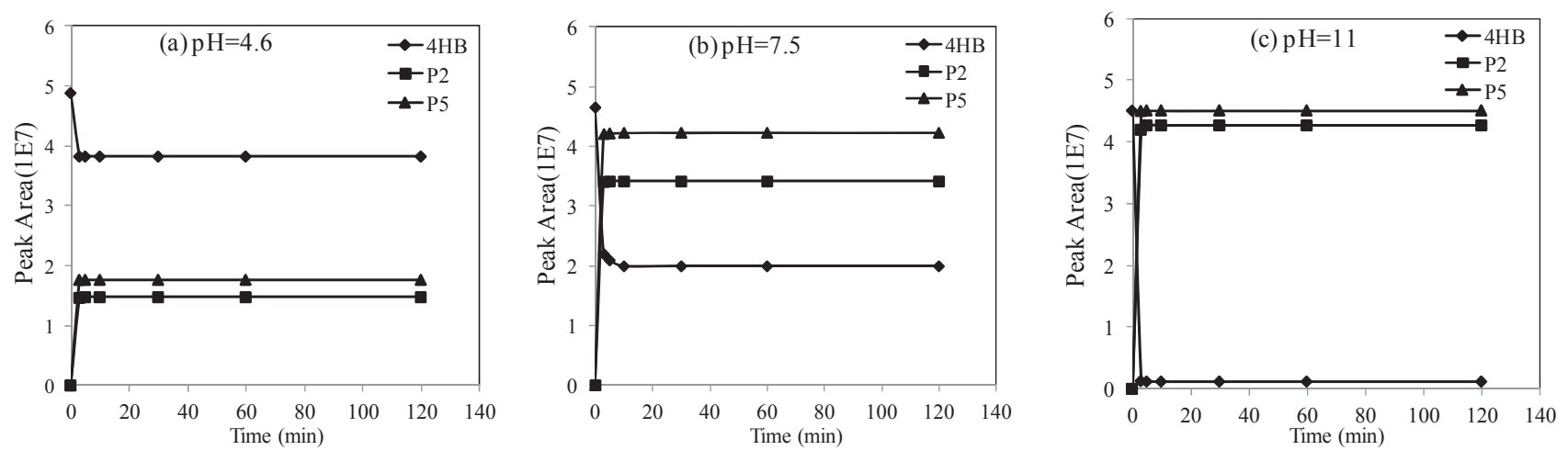

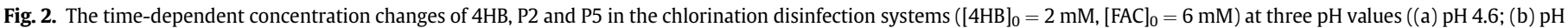
7.5; (c) pH 11.0). 
(a) $\mathrm{pH} 4.6$

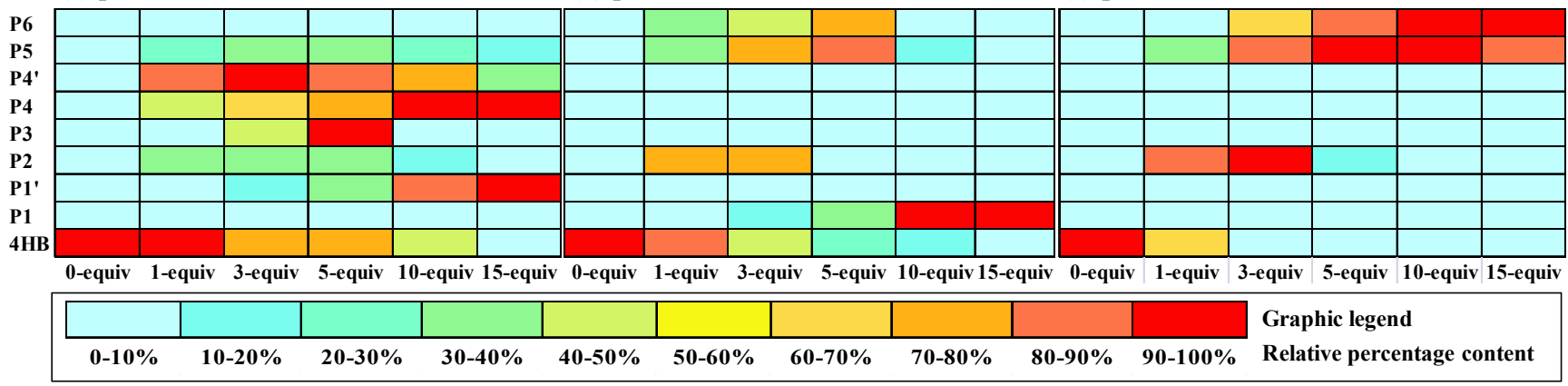

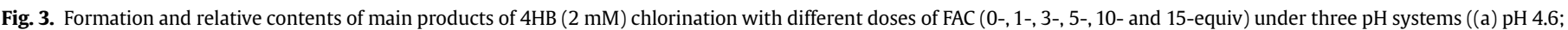

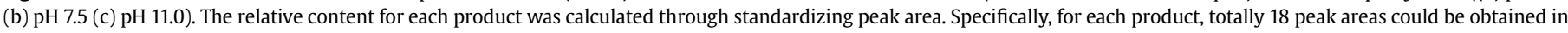

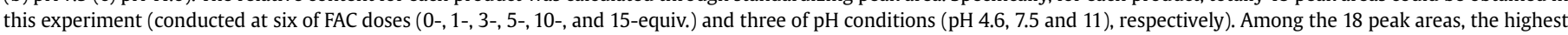

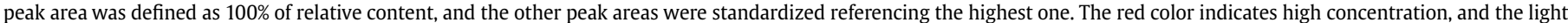

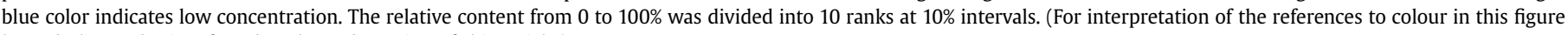
legend, the reader is referred to the web version of this article.)

\subsection{Acute toxicity variation}

After chlorination treatment of $4 \mathrm{HB}$ under different operating conditions, the acute toxicity of the reaction mixtures were preliminarily screened using Photobacterium bioassay. The acute toxicity changes of $4 \mathrm{HB}$ before and after chlorination treatment (1 h) under various dosages of FAC (1-, 3-, 5-, 10- and 15-equiv to $4 \mathrm{HB})$ and $\mathrm{pH}(4.6,7.5$ and 11.0$)$ are shown in Fig. 4. It can be observed that the toxicity decreased slightly when the FAC dosage increased from 0 to 3-equiv, followed by a sudden increase at the FAC dosage of 5-equiv, then decreased with the FAC increasing in acid system. And the toxicity increased and then decreased with the increasing FAC dosages in neutral system, while the acute toxicity increased straightly in alkaline system. In order to explore the relationship between the toxicity and products formation, one of intermediates P5 in alkaline chlorination system was prepared, and the acute toxicity was measured. Fig. S7 shows the toxicity results of $4 \mathrm{HB}$ and $\mathrm{P} 5$, the toxicity of $\mathrm{P} 5$ is much higher than $4 \mathrm{HB}$, which imply that the formation of $\mathrm{P} 5$ has positive contribution to the toxicity increase in $4 \mathrm{HB}$ chlorination system. By analyzing the relationship between the toxicity and products distribution (Fig. S8), the formation of P5 has a significant contribution to the toxicity increase. Of course, the combinatorial effects of all the

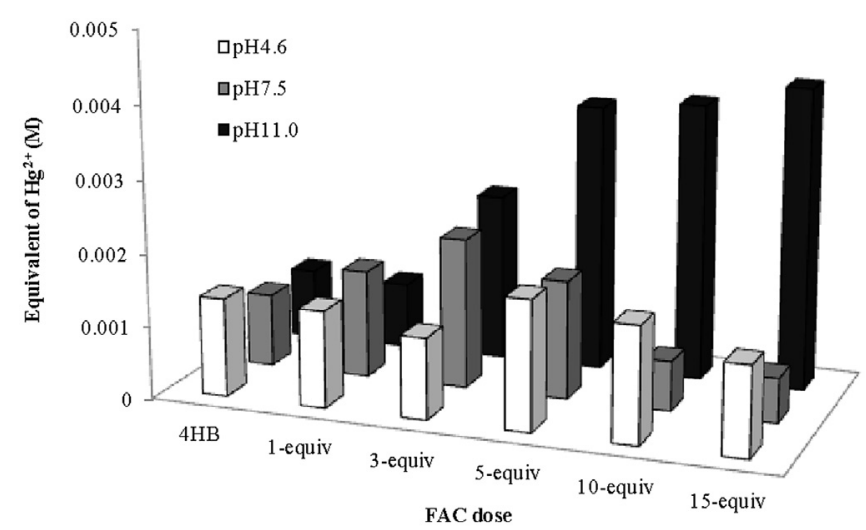

Fig. 4. Acute toxicity of reaction mixtures of $4 \mathrm{HB}$ chlorination system at three $\mathrm{pH}$ values ( $\mathrm{pH} 4.6$; $\mathrm{pH} 7.5 ; \mathrm{pH} 11.0$ ). products in the reaction mixtures would not be ignored.

\subsection{Environmental significance}

The previous experiments were conducted in pure water matrix, while if the transformation can be repeated in real ambient water matrix is still unknown. Therefore, two ambient water samples were collected from suburban Beijing, China. One sample was effluent of a sewage treatment plant (concentration of dissolvable organic carbon: $5.1 \mathrm{mg} \mathrm{L}^{-1}$; concentration of ammonia nitrogen: $0.2 \mathrm{mg} \mathrm{L}^{-1} ; \mathrm{pH}: 8.2$ ), and the other was lake water (concentration of dissolvable organic carbon: $12.6 \mathrm{mg} \mathrm{L}^{-1}$; concentration of ammonia nitrogen: $0.1 \mathrm{mg} \mathrm{L}^{-1}$; pH 7.7). The $4 \mathrm{HB}(1 \mu \mathrm{M})$ was spiked into water samples and chlorination disinfection experiments were conducted (FAC dose: 15 -equiv, ca. $1.5 \mathrm{mg} \mathrm{L}^{-1}$, similar to the FAC dose used in the chlorination disinfection practices; period: $1 \mathrm{~h}$ ). As shown in Fig. 5, P5 was detected within both water samples after chlorination treatment, while P2 was only found in the lake water sample after chlorination treatment. The occurrence of chlorinated products indicated that the similar transformation mechanisms of $4 \mathrm{HB}$ can be repeated in practical water chlorination disinfection process, and the potential risk should be concerned due to the formation of toxic chlorinated products.

\section{Conclusions}

4HB can be rapidly transformed in chlorination disinfection treatment at various $\mathrm{pH}$ values and FAC dosages. Seven products were identified out of eight detected transformation products. Three types of reactions such as chlorination substitution, BaeyerVilliger oxidation, ester hydrolysis were involved in chlorination disinfection process. The $\mathrm{pH}$ conditions affected the occurrence of reaction types, and FAC dosages affected the extent of reactions. Especially, the acute toxicity had a significant increase during the chlorination process, implying the formation of chlorinated products with higher toxicities relative to $4 \mathrm{HB}$. The 3,5-dichloro-4-HB had positive contribution to the toxicity increase in chlorination system. Moreover, the transformation of $4 \mathrm{HB}$ had also been confirmed by the occurrence of major toxic chlorinated product 3,5-dichloro-4-HB in real chlorination disinfection practices. The present study would throw more light on the transformation characteristics of BPs UV filters in chlorination disinfection 

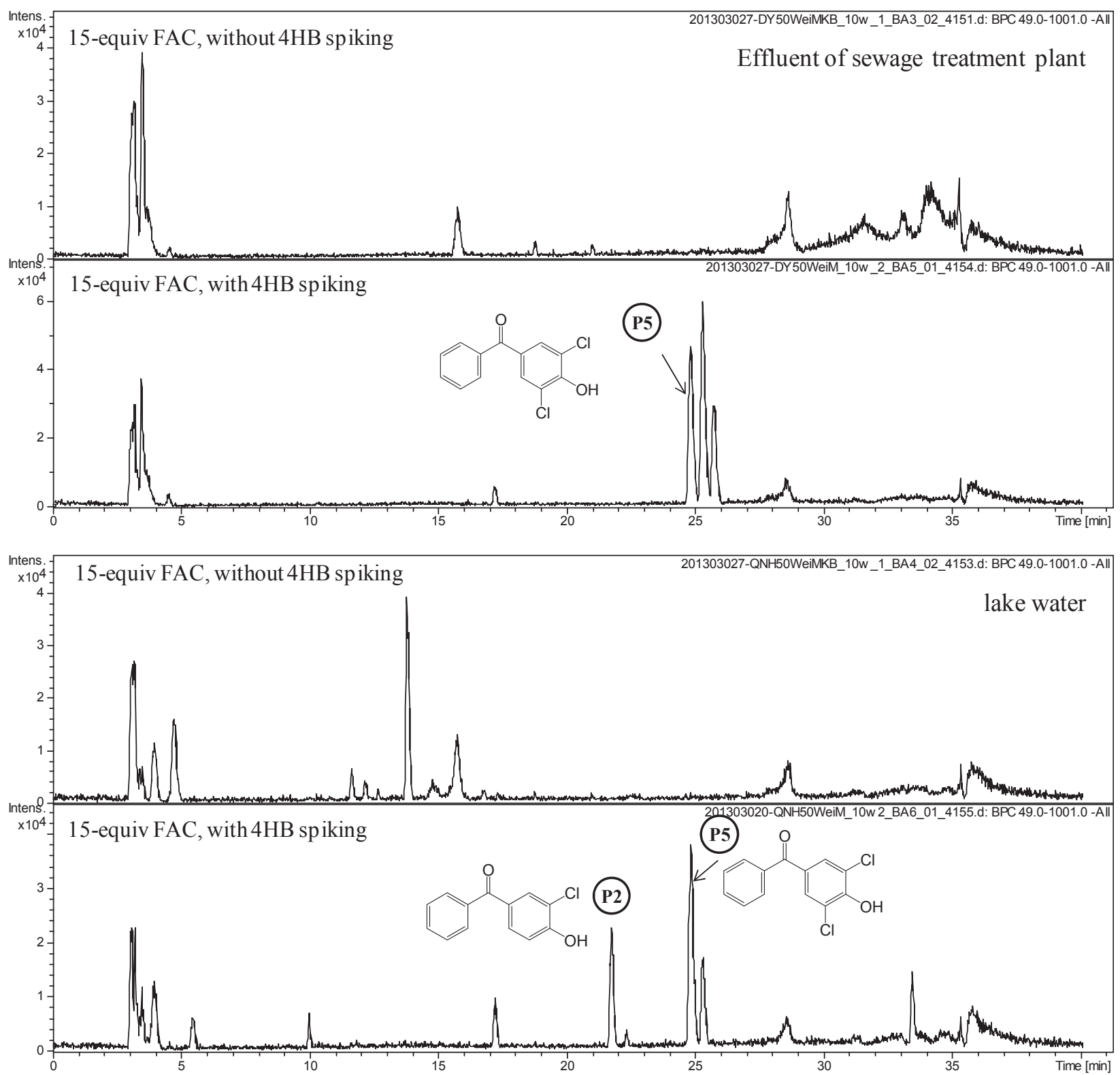

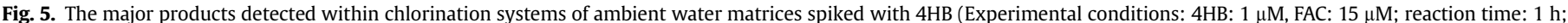
pH: 8.2 (effluent of sewage treatment plant) and 7.7 (lake water)).

practices, and provide a scientific evidence for optimizing the operating parameters for chlorination disinfection process.

\section{Acknowledgments}

This study was financially supported by the National Natural Science Foundation of P.R. China (Grant No. 21577154, 21377143 and 21590814).

\section{Appendix A. Supplementary data}

Supplementary data related to this article can be found at http:// dx.doi.org/10.1016/j.chemosphere.2016.04.005.

\section{References}

Balmer, M.E., Buser, H.R., Muller, M.D., Poiger, T., 2005. Occurrence of some organic
UV filters in wastewater, in surface waters, and in fish from Swiss Lakes. Envion. Sci. Technol. 39 (4) 953-962.

Christin, J.W., Petra, Y.K., Armin, K.Z., Karl, F., 2007. Effects of the UV filter benzophenone-2 on reproduction in fish. Toxicol. Appl. Pharmacol. 225, 255-266.

EEC (European Economic Community), 1983. Council Directive 83/574/EEC of 26 October 1983 Amending for the Third Time Directive 76/768/EEC on the Approximation of the Laws of the Member States Relating to Cosmetic Products, 332, pp. 38-42.

FDA (US Food and Drug Administration), 1999. Sunscreen drug products for overthe-counter human use, 21 CFR, Parts 310, 352, 700, and 740, RIN 0910-AA01 final monograph. Final rule. Fed. Regist. Rules Regs 64, 27666-27963.

Felix, T., Hall, B.J., Brodbelt, J.S., 1998. Determination of benzophenone-3 and metabolites in water and human urine by solid-phase microextraction and quadrupole ion trap GC-MS. Anal. Chim. Acta 371, 195-203.

Fluck, E.R., Poirier, L.A., Ruelius, H.W., 1976. Evaluation of a DNA polymerasedeficient mutant of E. coli for the rapid detection of carcinogens. Chem-Biol. Interact. 15 (3), 219-231.

French, J.E. 1992. NTP technical report on toxicity studies of 2-hydroxy-4-methoxy benzophenone (CAS No. 131-57-7) adminstered topically and in dosed feed to F344/N Rats and B6C3F1 Mice. Toxic. Rep. Ser. 21, E1-E14.

Grzegorz, N.J., Beata, R., Jozef, S., 1997. Evaluation of toxicity of medical devices 
using Spirotox and Microtox tests: I. toxicity of selected toxicants in various diluents. J. Biomed. Mat. Res. 35 (1), 101-105.

Hany, J., Nagel, R., 1995. Nachweis von UV-filter substanzen in muttermilch. Dtsch. Lebensm. Rundsch. 91, 341-345 (in Ger).

Jeon, H.K., Chung, Y., Ryu, J.C., 2006. Simultaneous determination of benzophenone -type UV filters in water and soil by gas chromatography-mass spectrometry. J. Chromatogr. A 1131, 192-202.

Jeon, H.K., Sarma, S.N., Kim, Y.J., Ryu, J.C., 2007. Forward gene mutation assay of seven benzophenone-type UV filters using L5178Y mouse lymphoma cell. Nat. Rev. Mol. Cell. Biol. 3, 23-30.

Kim, S., Choi, K., 2014. Occurrences, toxicities, and ecological risks of benzophenone-3, a common component of organic sunscreen products: a minireview. Environ. Int. 70, 143-157.

Liu, J.Q., Zhang, X.R., 2014. Comparative toxicity of new halophenolic DBPs in chlorinated saline wastewater effluents against a marine alga: halophenolic DBPs are generally more toxic than haloaliphatic ones. Water Res. 65, 64-72.

Louis, G.M.B., Kannan, K., Sapra, K.J., Maisog, J., Sundaram, R., 2014. Urinary concentrations of benzophenone-type ultraviolet radiation filters and couples' fecundity. Am. J. Epidemiol. 180 (12), 1168-1175.

Ma, R., Cotton, B., Lichtensteiger, W., Schlumpf, M., 2003. UV filters with antagonistic action at androgen receptors in the MDA-kb2 cell transcriptionalactivation assay. Toxicol. Sci. 74 (1), 43-50.

Manasfi, T., Storck, V., Ravier, S., Demelas, C., Coulomb, B., Boudenne, J.L., 2015. Degradation products of benzophenone-3 in chlorinated seawater swimming pools. Envion. Sci. Technol. 49, 9308-9316.

Moloney, F.J., Collins, S., Murphy, G.M., 2002. Sunscreens: safety, efficacy and appropriate use. Am. J. Clin. Dermatol 3 (3), 185-191.

Mortelmans, K., Haworth, S., Lawlor, T., Speck, W., Tainer, B., Zeiger, E., 1986. Salmonella mutagenicity tests: II. Results from the testing of 270 chemicals. Environ. Mut. 8, 1-55.

Negreira, N., Canosa, P., Rodriguez, I., Ramil, M., Rubi, E., Cela, R., 2008. Study of some UV filters stability in chlorinated water and identification of halogenated by-products by gas chromatography-mass spectrometry. J. Chromatogr. A 1178, $206-214$.

Negreira, N., Rodriguez, I., Rodil, R., Cela, R., 2012. Assessment of benzophenone-4 reactivity with free chlorine by liquid chromatography quadrupoe time-offlight mass spectrometry. Anal. Chim. Acta 743, 101-110.

Pan, Y., Zhang, X.R., Li, Y., 2016. Identification, toxicity and control of iodinated disinfection byproducts in cooking with simulated chlor(am)inated tap water and iodized table salt. Water Res. 88, 60-68.

Richardson, S.D., 1998. Drinking water disinfection by-products. In: Meyers, R.A. (Ed.), The Encyclopedia of Environmental Analysis and Remediation, vol. 3. Wiley, New York, pp. 1398-1421.

Richardson, S.D., Plewa, M.J., Wagner, E.D., Schoeny, R., DeMarini, D.M., 2007. Occurrence, genotoxicity, and carcinogenicity of regulated and emerging disinfection by-products in drinking water: a review and roadmap for research. Mut. Res. 636, 178-242.

Rodil, R., Quintana, J.B., Lopez-Mahia, P., Muniategui-Lorenzo, S., Prada-
Rodriguez, D., 2008. Multiclass determination of sunscreen chemicals in water samples by liquid chromatography - tandem mass spectrometry. Anal. Chem. 80 (4), 1307-1315.

Roelandts, R., Vanhee, J., Bonamie, A., Kerkhofs, L., Degreef, H., 1983. A survey of ultraviolet absorbers in commercially available sun products. Int. J. Dermatol 22 (4), 247-255

Schlumpf, M., Cotton, B., Conscience, M., Haller, V., Steinmann, B., Lichtensteiger, W., 2001. In vitro and in vivo estrogenicity of UV screens. Environ. Health Persp 109 (3), 239-244.

Schreurs, R.H.M.M., Sonneveld, E., Jansen, J.H.J., Seinen, W., van der Burg, B., 2005. Interaction of polycyclic musks and UV filters with the estrogen receptor (ER), androgen receptor (AR), and progesterone receptor (PR) in reporter gene bioassays. Toxicol. Sci. 83 (2), 264-272.

Schwarzenbach, R.P., Gschwend, P.M., Imboden, D.M., 2003. Environmental Organic Chemistry, second ed. John Wiley and Sons Inc, Hoboken, New Jersey, pp. $166-172$.

SJP (The Society of Japanese Pharmacopoeia), 1985. Japanese Standard of Cosmetic Ingredients, second ed. Yakuji Nippo Ltd., Tokyo.

Stenback, F., 1977. Local and systematic effects of commonly used cutaneous agents - lifetime studies of 16 mice and rabbits. Acta Pharmacol. Toxicol 41, 417-431.

Suzuki, T., Kitamura, S., Khota, R., Sugihara, K., Fujimoto, N., Ohta, S., 2005. Estrogenic and antiandrogenic activities of 17 benzophenone derivatives used as UV stabilizers and sunscreens. Toxicol. Appl. Pharmacol 203, 9-17.

TGA (Therapeutic Goods Administration), July 2003. Australian Regulatory Guidelines for OTC Medicines. Therapeutic goods administration, Australia.

Tomson, M.B., Dauchy, J., Hutchins, S., Curran, C., Cook, C.J., Ward, C.H., 1981 Groundwater contamination by trace level organics from a rapid infiltration site. Water Res. 15 (9), 1109-1116.

Xiao, M., Wei, D.B., Yin, J.X., Wei, G.H., Du, Y.G., 2013. Transformation mechanism of benzophenone-4 in free chlorine promoted chlorination disinfection. Water Res. 47, 6223-6233.

Yang, M.T., Zhang, X.R., 2013. Comparative developmental toxicity of new aromatic halogenated DBPs in a chlorinated saline sewage effluent to the marine polychaete platynereis dumerilii. Environ. Sci. Technol. 47 (19), 10868-10876.

Ye, Z.F., Zhao, Q.L., Zhang, M.H., Gao, Y.C., 2011. Acute toxicity evaluation of explosive wastewater by bacterial bioluminescence assays using a freshwater luminescent bacterium, Vibrio qinghaiensis sp. Nov. J. Hazard. Mat. 186, 1351-1354.

Zeiger, E., Anderson, B., Haworth, S., Lawlor, T., Mortelmans, K., Speck, W., 1987. Salmonella Mutagenicity tests: III. Results from the testing of 255 chemicals. Environ. Mut. 9, 61-109.

Zenker, A., Schmutz, H., Fent, K., 2008. Simultaneous trace determination of nine organic UV-absorbing compounds (UV filters) in environmental samples. J. Chromatogr. A 1202, 64-74.

Zhao, H.M., Wei, D.B., Li, M., Du, Y.G., 2013. Substituent contribution to the genotoxicity of benzophenone-type UV filters. Ecotoxicol. Environ. Safe 95, 241-246.

Zwiener, C., Richardson, S.D., De Marini, D.M., Grummt, T., Glauner, T., Frimmel, F.H., 2007. Drowning in disinfection byproducts? Assessing swimming pool water. Environ. Sci. Technol. 41, 363-372. 